\title{
Effect of 1110 MBq Radioiodine in Reducing Thyroid Volume in Multinodular Goiter: A New Protocol
}

\author{
Armando Flores-Rebollara, c, Aida Ruiz-Juvera ${ }^{\mathrm{b}}$, Guadalupe Lopez-Carrasco ${ }^{\mathrm{b}}$, \\ Ofelia Gonzalez-Trevino ${ }^{\mathrm{b}}$
}

\begin{abstract}
Background: There is no consensus on the optimal treatment of multinodular goiter (MNG), but in the past few years, the use of radioiodine has increased. This study's objective was to evaluate adjuvant methimazole (MMI) therapy to increase and standardize radioiodine uptake (RAIU) with a fixed therapeutic ${ }^{131} \mathrm{I}$ dose of $1110 \mathrm{MBq}(30 \mathrm{mCi})$.
\end{abstract}

Methods: Our study included 5 women with MNG treated with MMI, 10 - $15 \mathrm{mg}$ /day for 2 to 4 months, prior to the administration of $1110 \mathrm{MBq}{ }^{131} \mathrm{I}$ (30 $\mathrm{mCi}$ ); none of the patients developed hypothyroidism during MMI therapy and had average basal TSH levels of $0.32 \pm 0.39 \mathrm{mIU} / \mathrm{L}$ that increased to $2.6 \pm 0.9 \mathrm{mIU} / \mathrm{L}(\mathrm{P}=0.07)$.

Results: RAIU increased from $25.6 \pm 8.7 \%$ to $49.2 \pm 8.3 \%$ ( $\mathrm{P}=$ $0.003)$. All patients were followed for 12 months: median thyroid volume (TV) decreased from $77.2 \mathrm{~mL}(32.9$ - 124.2) to $48.8 \mathrm{ml}$ (12.4 - 68.9) with an average decrease of $46.4 \pm 14.8 \%(\mathrm{P}=0.01)$. All patients developed hypothyroidism during the first 6 months after radioiodine therapy.

Conclusions: This new therapeutic protocol using MMI as adjuvant therapy is effective in increasing RAIU as well as the deleterious effects of ${ }^{131} \mathrm{I}$, without increasing the required dose, but leading to thyroid volume decreases similar to those reported with the use of recombinant human thyrotropin (rhTSH) or higher radioiodine doses.

Keywords: Methimazole; Radioiodine; Multinodular goiter; Thy-

\footnotetext{
Manuscript accepted for publication Aprile 3, 2013

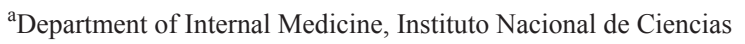
Medicas y Nutricion "Salvador Zubira", DF, Mexico

${ }^{\mathrm{b}}$ Department of Nuclear Medicine, Instituto Nacional de Ciencias Medicas y Nutricion "Salvador Zubira”, DF, Mexico

${ }^{\mathrm{c}}$ Corresponding author: Armando Flores Rebollar, Department of Internal Medicine, Instituto Nacional de Ciencias Medicas y Nutricion "Salvador Zubiran", Vasco de Quiroga \#15, Col. Seccion XVI, Tlalpan, DF; CP 14000, Mexico. Email: afcalatrava@yahoo.com
}

doi: http://dx.doi.org/10.4021/jocmr1361w roid; Uptake; ${ }^{131} \mathrm{I}$; Treatment; Hyperthyroidism

\section{Introduction}

Worldwide, multinodular goiter (MNG) is a common thyroid pathological entity, frequently associated to a deficient iodine intake and other factors [1]. Clinical manifestations hinge on glandular growth, compression and functional autonomy.

No consensus has been reached in terms of MNG treatment and its optimal management remains controversial [2]; therapeutic options include levothyroxine (LT4), surgery and radioiodine. Suppressive treatment with LT4 is discouraged due to the possible risk of causing sub-clinical or overt hyperthyroidism as well as its low efficacy when compared with other treatment modalities [3]. Total or sub-total thyroidectomy effectively decrease thyroid volume and its related complications, but carry the risk of anesthetic and surgical complications [2]. The use of ${ }^{131} \mathrm{I}$ in the treatment of MNG has increased in the past few years as a result of its use in hyperthyroidism for over 70 years [4]. In some European and Latin American countries, ${ }^{131}$ I therapy replaced surgery as the treatment of choice in patients with MNG [5]. This change was a result of several factors: many patients prefer nonsurgical treatment, ${ }^{131} \mathrm{I}$ therapy can be conducted on an ambulatory basis and cost-benefit analysis favors radioiodine. MNG volume reduction depends on the basal thyroid volume, the amount of administered ${ }^{131} I$ and the gland's uptake capacity. Published reports on the use of ${ }^{131} \mathrm{I}$ have referred thyroid volume reductions of 35 to $60 \%[4,6]$. The use of ${ }^{131} \mathrm{I}$ is limited by low and heterogeneous radioiodine uptake (RAIU), particularly in regions or countries with normal diets or those with high iodine intake. A low RAIU leads to a less effective treatment and renders this treatment modality more difficult [4]. Low RAIU can be overcome with the use of recombinant human thyrotropin (rhTSH) but it has only been approved for well-differentiated thyroid cancer; regardless in the past decade, its use as coadjuvant MNG therapy in association with ${ }^{131} \mathrm{I}$, in order to increase RAIU and obtain a homogeneous ${ }^{131} \mathrm{I}$ distribution, has become more frequent 
[7-12]. The obtained results have been comparable to the use of ${ }^{131} \mathrm{I}$ but with the advantages of lower dosage and the possibility of ambulatory therapy.

Treatment with rhTSH is expensive and in some countries, the price is prohibitive. A Brazilian group [13] recently reported that increasing endogenous TSH after methimazole (MMI) therapy increased RAIU from 21 to $78 \%$ and decreased thyroid volume by $46 \%$ after ${ }^{131} \mathrm{I}$ administration; $\mathrm{TSH}$ was increased to an average of $11.7 \pm 5.4 \% \mathrm{mIU} / \mathrm{L}$. Similar results have been reported by others [14].

The purpose of this study is to attempt this new RAIU increase protocol with methimazole and endogenous TSH, in a group of patients with $\mathrm{MNG}$ treated with a fixed ${ }^{131}$ I dose of $1110 \mathrm{MBq}(30 \mathrm{mCi})$, evaluate the results and compare them with those reported in the literature.

\section{Materials and Methods}

\section{Patients}

Five (5) MNG patients were selected from the Internal Medicine Outpatient Clinic of the "Instituto Nacional de Ciencias Medicas y Nutricion" "Salvador Zubiran". All were newly admitted patients for the management of their thyroid problem and in search of an alternative to surgical treatment (thyroidectomy); they had never been treated with MMI, thyroid hormones or radioactive iodine. None had associated severe comorbidities or heart disease. The study followed the Institute's Bioethics Committee's guidelines and all patients signed a consent form.

Basal thyroid volume (TV) was determined by ultrasound in all cases and malignancy was ruled out by ultrasound-guided fine needle biopsy of suspicious nodules. Serum TSH, free T4 (FT4), total T3 (TT3), anti-thyroid peroxidase antibodies (TPOAb) and anti-thyroglobulin antibodies (TgAb) were determined before the thyroid scan and basal ${ }^{131}$ I measurement. Three patients had sub-clinical hyperthyroidism and two were euthyroid; all were treated with MMI, 10 - $15 \mathrm{mg}$ /day during their first visit and after the previously mentioned evaluation. Subsequent visits were scheduled every 4 weeks at which time TSH, FT4 and TT3 levels were again determined. We attempted to maintain FT4 above $9.0 \mathrm{pmol} / \mathrm{L}$ and avoid hypothyroidism; the degree of clinical hypothyroidism was estimated using the score developed by Zulewski et al [15] (Hypothyroid, more than 5 points; euthyroid less than 3 points, intermediate 3 - 5 points); MMI dosage was decreased as necessary. The goal was to increase by $50 \%$ the basal RAIU without conditioning clinical hypothyroidism; once reached, $1110 \mathrm{MBq}(30 \mathrm{mCi})$ ${ }^{131}$ I were administered orally and the patients were re-evaluated monthly for the first 4 months and later, every 2 months for a year. Clinical signs of dysthyroidism, thyroid volume by US, TSH, FT4, TT3, TPOAb and TgAb were determined at each visit.

\section{Methods}

A thyroid scan with $1.85 \mathrm{MBq}(50 \mu \mathrm{Ci}){ }^{131} \mathrm{I}$ and 24 hour uptake determination were conducted in all patients (Gammacamara, Model E-Cam, Siemens). Thyroid ultrasound was performed with portable General Electric (GE) equipment and a $60 \mathrm{~mm}$ lineal transducer $(7.5 \mathrm{MHz})$. Nodules with suspicious characteristics were biopsied under ultrasound guidance. Thyroid volume was determined by ultrasound and the volume of each thyroid lobe was calculated with the ellipsoid volume equation $(0.52 \times$ width $\times$ height $\times$ length $)$. Total thyroid volume was obtained by adding the volume of both lobes.

Serum TSH, FT4, TT3, TPOAb and TgAb concentrations were measured by radioimmunoassay. FT4 had an analytical sensitivity of $0.65 \mathrm{pmol} / \mathrm{L}$ (normal range: $9.0-23.2$ $\mathrm{pmol} / \mathrm{L})$, the TT3 assay had an analytical sensitivity of 0.15 nmol/L (normal range: 0.9 - $2.9 \mathrm{nmol} / \mathrm{L}$ ), TgAb had an analytical sensitivity of $2.0 \mathrm{IU} / \mathrm{mL}$ (normal values: under $30 \mathrm{IU} /$ mL (RIA-gnost ${ }^{\circledR}$ FT4, RIA-gnost ${ }^{\circledR}$ T3, TGAB ONE STEP ${ }^{\circledR}$, Cisbio Bioassays, France). The assay used in TPOAb determination had an analytical sensitivity of $1.9 \mathrm{IU} / \mathrm{mL}$ (normal values: under $100 \mathrm{IU} / \mathrm{mL}$ ); TSH was determined by immunoradiometric assay (IRMA) and had an analytical sensitivity of $0.005 \mathrm{mIU} / \mathrm{L}$ (normal range: 0.3 to $4.0 \mathrm{mIU} / \mathrm{L}$ ) (Anti-hTPO RIA KIT ${ }^{\circledR}$, Turbo TSH ${ }^{125}$ I IRMA KIT $^{\circledR}$ Izotop Budapest, Hungary).

\section{Statistical analysis}

Statistical analysis was conducted with the SPSS 15.0 program (Chicago IL, USA). Results are presented as medians (ranges) or mean $\pm \mathrm{SD}$ and depending on the data's distribution, Kolmogorov-Smirnov's test.

Differences over time were analyzed with Student's paired t test. Statistical significance was established at $\mathrm{P}<$ 0.05 .

\section{Results}

All patients were female. One year after radioiodine administration, the median TV decreased from $77.2 \mathrm{~mL}(32.9$ - 124.2) to $48.8 \mathrm{ml}(12.4$ - 68.9). The average TV decrease was $46.4 \pm 14.8 \%(\mathrm{P}=0.010)$ (Table 1$)$.

The RAIU increase due to MMI pre-treatment went from $25.6 \pm 8.7 \%$ to $49.2 \pm 8.3 \%$ ( $\mathrm{P}=0.003)$. The effective ${ }^{131} \mathrm{I}$ released dose per gram of thyroid tissue was 8.47 $\pm 5.53 \mathrm{MBq}(229.0 \pm 149.6 \mu \mathrm{Ci})$. The initial MMI dose in all patients was $10 \mathrm{mg} /$ day except in one case that initially received $15 \mathrm{mg}$ /day. Three (3) patients reached the RAIU goal within 2 months, and the others, by the third and fourth 


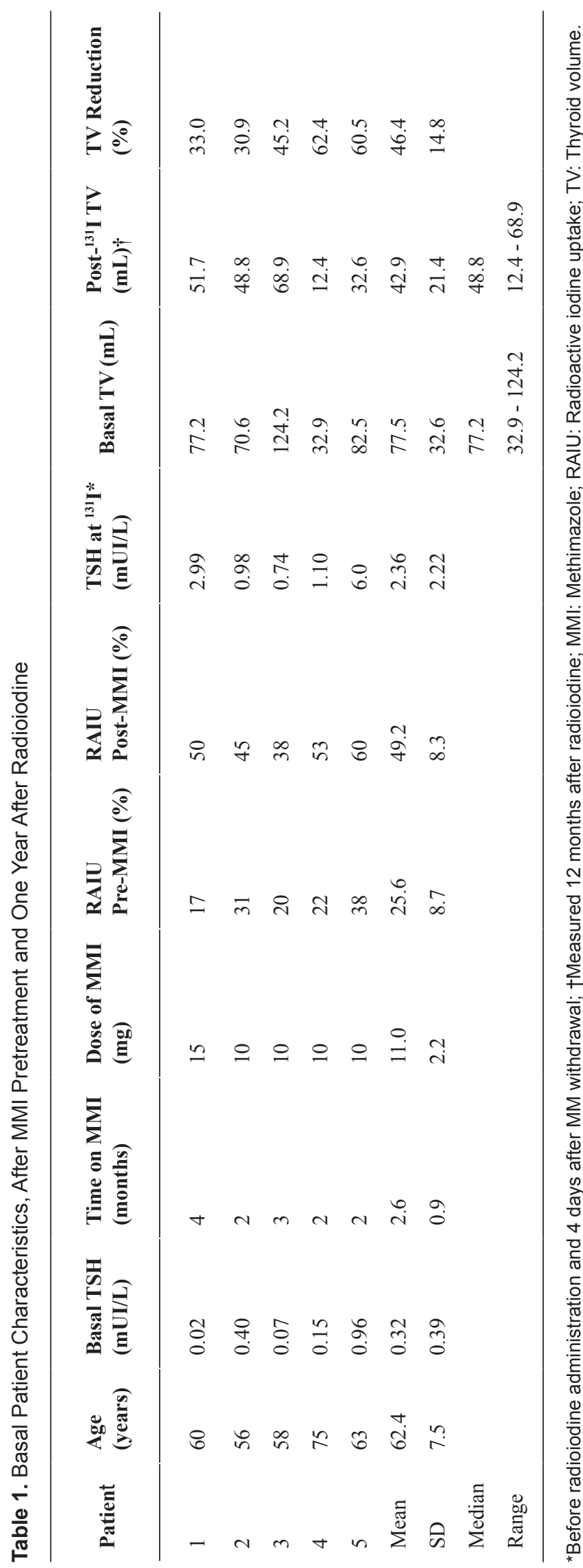

month of therapy; ${ }^{131} \mathrm{I}$ was administered on the fourth day after MMI withdrawal. Our patients did not tolerate the initial MMI doses for more than 4 weeks since they all reached the lower FT4 limits and 2 patients developed mild hypothyroidism symptoms, (Zulewski'score) [15]. Average basal TSH was $0.32 \pm 0.39 \mathrm{mIU} / \mathrm{L}$ and increased to $2.6 \pm 0.9 \mathrm{mIU} / \mathrm{L}(\mathrm{P}$ $=0.07$ ) after the brief exposure to MMI.

After ${ }^{131} \mathrm{I}$ administration, only one patient developed severe radiation-related thyroiditis (case 5) that required steroid therapy for a week. None of the patients presented an increase in anti-thyroid antibodies, except for one case whose $\mathrm{TPOAb}$ increased seven months after ${ }^{131} \mathrm{I}$ administration but with no associated hyperthyroidism or clinical findings suggestive of Grave's disease.

All patients developed hypothyroidism after radioactive iodine within the first 6 months after therapy. Clinical hypothyroidism was diagnosed when Zulewski's score was above 5 points in association with a FT4 level $<9.0 \mathrm{pmol} / \mathrm{L}$ and a TSH level $>4.0 \mathrm{mIU} / \mathrm{L}$. Thyroid hormone substitution therapy was initiated with per os sodium levothyroxine; the dose was calculated on a $1.6 \mu \mathrm{g} / \mathrm{kg} /$ day basis, administering a total of $25 \mu \mathrm{g} /$ day that was progressively increased until TSH was steadily maintained between 1.0 and $3.0 \mathrm{mIU} / \mathrm{L}$ and hypothyroidism symptoms resolved.

\section{Discussion}

Although this study included a small number of patients, it showed that pre-treatment with MMI increases radioiodine uptake and renders it homogeneous without compromising its efficacy; it increased its deleterious effects and hence, decreased TV. In contrast with the previous study [13], we did not determine a target TSH level; the purpose was to reach a $50 \%$ or above increase in the basal RAIU after MMI treatment. This was achieved with minimal MMI doses, still maintaining TSH within normal limits and avoiding clinical hypothyroidism and observing symptomatic improvement. The decreases observed in our study were similar to those in the previously referred study (46.4 vs. $46.2 \%$ ) [13] and when compared with studies that used a fixed dose of $1110 \mathrm{MBq}$ $(30 \mathrm{mCi}){ }^{131} \mathrm{I}$, our results are similar or superior to ${ }^{131} \mathrm{I}$ with or without rhTSH pretreatment $[9,16,17]$. The mechanism by which the thyroid RAIU increased can only be explained by TSH-mediated activation of the sodium-iodine symporter (NIS) [18]. Although the TSH increase was not significant, the tendency is clear but perhaps blunted by the small number of patients. Although the reported data in the literature may differ in terms of pre-treatment with anti-thyroid drugs and the effectiveness of radioiodine in benign thyroid disease, this study and the experience in Brazil have shown the benefits of pre-treatment, particularly in the improvement of thyroid RAIU. Perhaps, the moment of MMI withdrawal at the time of ${ }^{131}$ I administration, under 7 days in both studies, 
may influence these positive results [18, 19]. Surprisingly, all our patients developed hypothyroidism after therapy; this could be explained by increased radioiodine sensitivity in our patients or to the fortuitous aggregation of individuals with radiosensitivity per se. However, it has been shown that individuals pre-treated with $\mathrm{MMI}$ and undergoing ${ }^{131} \mathrm{I}$ therapy for MNG have a higher incidence of hypothyroidism than those that are not pre-treated with MMI [6].

As in the Brazilian study [13], we decided to use a fixed radioiodine dose, the maximum dosage was allowed by Mexican guidelines in ambulatory treatment; moreover, most patients had large goiters and low RAIU. The difference hinged on establishing thyroid uptake as the treatment goal and therefore avoiding the possibility of developing clinical hypothyroidism. The risk of presenting side effects due to MMI was averted by using low doses and this may have also prevented an increase in TV by substantially increasing TSH levels. The average time period required to reach this uptake goal was $2.6 \pm 0.9$ months, an appropriate time period considering the delays in radioiodine treatments within an institutional medicine context in our country.

Although the new American Thyroid Association (ATA)/American Association of Clinical Endocrinologists (AACE) [20] guidelines recommend ${ }^{131} \mathrm{I}$ as the therapy of choice in MNG, they do not support the use of rhTSH as an adjuvant to radioiodine therapy; it is not clear, however, whether pretreatment with MMI in toxic MNG is recommendable. They do refer in guideline number 35 , that the Brazilian study obtained similar results to the use of rhTSH with MMI pretreatment.

Our study is small, heterogeneous and only includes female patients but we have proven as in the South American studies, that this therapeutic option effectively decreases TV in MNG. Future studies should focus on homogeneous groups and compare the effects of this alternative with the use of rhTSH in the treatment of MNG.

\section{Declaration of Interest}

The authors had no conflicts of interest to declare in relation to this article.

\section{Author Contribution}

Armando Flores-Rebollar: Concept/design, Data analysis/ Interpretation, Statistics/data collection, Drafting article and Critical revision of article; Aida Ruiz-Juvera: Data analysis/ Interpretation, Data collection, Drafting article and Critical revision of article; Guadalupe Lopez-Carrasco: Data analysis/Interpretation, Data collection and Critical revision of article; Ofelia Gonzalez-Trevino: Data analysis/Interpretation, Data collection and Critical revision of article.

\section{References}

1. Derwahl M, Studer H. Multinodular goitre: 'much more to it than simply iodine deficiency'. Baillieres Best Pract Res Clin Endocrinol Metab. 2000;14(4):577-600.

2. Hegedus L, Bonnema SJ, Bennedbaek FN. Management of simple nodular goiter: current status and future perspectives. Endocr Rev. 2003;24(1):102-132.

3. Wesche MF, Tiel VBMM, Lips P, Smits NJ, Wiersinga WM. A randomized trial comparing levothyroxine with radioactive iodine in the treatment of sporadic nontoxic goiter. J Clin Endocrinol Metab. 2001;86(3):998-1005.

4. Bonnema SJ, Hegedus L. A 30-year perspective on radioiodine therapy of benign nontoxic multinodular goiter. Curr Opin Endocrinol Diabetes Obes. 2009;16(5):379384.

5. Diehl LA, Garcia V, Bonnema SJ, Hegedus L, Albino $\mathrm{CC}$, Graf $\mathrm{H}$. Management of the nontoxic multinodular goiter in Latin America: comparison with North America and Europe, an electronic survey. J Clin Endocrinol Metab. 2005;90(1):117-123.

6. Nygaard B, Hegedus L, Ulriksen P, Nielsen KG, Hansen JM. Radioiodine therapy for multinodular toxic goiter. Arch Intern Med. 1999;159(12):1364-1368.

7. Nieuwlaat WA, Huysmans DA, van den Bosch HC, Sweep CG, Ross HA, Corstens FH, Hermus AR. Pretreatment with a single, low dose of recombinant human thyrotropin allows dose reduction of radioiodine therapy in patients with nodular goiter. J Clin Endocrinol Metab. 2003;88(7):3121-3129.

8. Albino CC, Mesa CO, Jr., Olandoski M, Ueda CE, Woellner LC, Goedert CA, Souza AM, et al. Recombinant human thyrotropin as adjuvant in the treatment of multinodular goiters with radioiodine. J Clin Endocrinol Metab. 2005;90(5):2775-2780.

9. Cubas ER, Paz-Filho GJ, Olandoski M, Goedert CA, Woellner LC, Carvalho GA, Graf H. Recombinant human TSH increases the efficacy of a fixed activity of radioiodine for treatment of multinodular goitre. Int J Clin Pract. 2009;63(4):583-590.

10. Romao R, Rubio IG, Tomimori EK, Camargo RY, Knobel M, Medeiros-Neto G. High prevalence of side effects after recombinant human thyrotropin-stimulated radioiodine treatment with $30 \mathrm{mCi}$ in patients with multinodular goiter and subclinical/clinical hyperthyroidism. Thyroid. 2009;19(9):945-951.

11. Fast S, Nielsen VE, Grupe P, Bonnema SJ, Hegedus L. Optimizing 131I uptake after rhTSH stimulation in patients with nontoxic multinodular goiter: evidence from a prospective, randomized, double-blind study. J Nucl Med. 2009;50(5):732-737.

12. Nielsen VE, Bonnema SJ, Boel-Jorgensen H, Grupe P, Hegedus L. Stimulation with $0.3-\mathrm{mg}$ recombinant human thyrotropin prior to iodine 131 therapy to improve 
the size reduction of benign nontoxic nodular goiter: a prospective randomized double-blind trial. Arch Intern Med. 2006;166(14):1476-1482.

13. Albino CC, Graf H, Sampaio AP, Vigario A, Paz-Filho GJ. Thiamazole as an adjuvant to radioiodine for volume reduction of multinodular goiter. Expert Opin Investig Drugs. 2008;17(12):1781-1786.

14. Pitoia F, Chervin R, Nunez S, Salvai ME, El Tamer E, Shere D, Niepomniszcze H. Development of Graves' Disease Following a Radioiodine dose for the Shrinkage of a Multinodular Goiter after using a novel protocolo. The Endocrinologist 2010;20(1):7-9.

15. Zulewski H, Muller B, Exer P, Miserez AR, Staub JJ. Estimation of tissue hypothyroidism by a new clinical score: evaluation of patients with various grades of hypothyroidism and controls. J Clin Endocrinol Metab. 1997;82(3):771-776.

16. Albino CC, Graf H, Paz-Filho G, Diehl LA, Olandoski M, Sabbag A, Buchpiguel C. Radioiodine plus recombinant human thyrotropin do not cause acute airway compression and are effective in reducing multinodular goiter. Braz J Med Biol Res. 2010;43(3):303-309.
17. Paz-Filho GJ, Mesa-Junior CO, Olandoski M, Woellner LC, Goedert CA, Boguszewski CL, Carvalho GA, et al. Effect of $30 \mathrm{mCi}$ radioiodine on multinodular goiter previously treated with recombinant human thyroid-stimulating hormone. Braz J Med Biol Res. 2007;40(12):16611670.

18. Ferreira AC, Lima LP, Araujo RL, Muller G, Rocha RP, Rosenthal D, Carvalho DP. Rapid regulation of thyroid sodium-iodide symporter activity by thyrotrophin and iodine. J Endocrinol. 2005;184(1):69-76.

19. Kubota S, Ohye H, Yano G, Nishihara E, Kudo T, Ito $\mathrm{M}$, Fukata S, et al. Two-day thionamide withdrawal prior to radioiodine uptake sufficiently increases uptake and does not exacerbate hyperthyroidism compared to 7-day withdrawal in Graves' disease. Endocr J. 2006;53(5):603-607.

20. Bahn Chair RS, Burch HB, Cooper DS, Garber JR, Greenlee MC, Klein I, Laurberg P, et al. Hyperthyroidism and other causes of thyrotoxicosis: management guidelines of the American Thyroid Association and American Association of Clinical Endocrinologists. Thyroid. 2011;21(6):593-646. 